\title{
Structural and mechanical properties of $\mathrm{TiB}_{2}$ and $\mathrm{TiC}$ prepared by self-propagating high-temperature synthesis/dynamic compaction
}

\author{
L. WANG, M. R. WIXOM \\ T/J Technologies, Inc., Northville, MI 48167, USA \\ L. T. THOMPSON \\ The University of Michigan, Department of Chemical Engineering, Ann Arbor, \\ MI 48109-2136, USA
}

\begin{abstract}
Titanium-diboride and titanium-carbide compacts with diameters of $100 \mathrm{~mm}$ and thicknesses of $25 \mathrm{~mm}$ were fabricated by self-propagating high-temperature synthesis/dynamic compaction (SHS/DC) of the elemental powders. Under the best conditions, the densities were greater than $99 \%$ and $96.8 \%$ of the theoretical densities for $\mathrm{TiB}_{2}$ and $\mathrm{TiC}$, respectively. The microhardness, compressive strength, and elastic modulus of the $\mathrm{TiB}_{2}$ prepared by the SHS/DC method were comparable to reported values for hot-pressed $\mathrm{TiB}_{2}$. While the microhardness and elastic modulus of the $\mathrm{TiC}$ compacts were comparable to those for hotpressed $\mathrm{TiC}$, the compressive strength was lower due to extensive cracks in the compacts. The $\mathrm{TiB}_{2}$ prepared using a low-purity boron powder ( $1-5 \%$ carbon impurity) compacted to higher densities and had less cracking than that prepared using a high-purity boron powder $(0.2 \%$ carbon). This result could have an impact on the cost of producing $\mathrm{TiB}_{2} / \mathrm{TiC}$ structural components by the SHS/DC process.
\end{abstract}

\section{Introduction}

There is growing interest in the use of titaniumdiboride and titanium-carbide ceramics because of their high melting points, hardness, compressive strength, excellent wear resistance, and light weight. In addition, they are thermally shock resistant and chemically stable. These properties make $\mathrm{TiB}_{2}$ and $\mathrm{TiC}$ attractive for applications including use in light armour, cutting tools, wear parts, and jet-engine components [1-5].

The fabrication of $\mathrm{TiB}_{2}$ and $\mathrm{TiC}$ ceramics by conventional sintering, hot pressing or hot isostatic pressing of $\mathrm{TiB}_{2}$ and $\mathrm{TiC}$ powders is costly because of the time-intensive and facility-intensive nature of these processes. The commercial application of $\mathrm{TiB}_{2}$ and TiC ceramics has thus been limited. A self-propagating high-temperature synthesis technique (SHS) when combined with dynamic compaction (DC) may provide an economic method for producing dense bodies of $\mathrm{TiB}_{2}$ and $\mathrm{TiC}$ from the elemental powders. The SHS process takes advantage of the extreme heat generated during the formation of some refractory materials. When a compact of the constituent elemental powders is ignited, the highly exothermic reaction propagates spontaneously and rapidly, and converts the reactants into a refractory product. This technique has attracted attention as a route to a variety of refractory materials including borides, carb- ides, nitrides, silicides and intermetallic compounds [6-21]. The SHS products, however, cannot be used directly as structural materials because they are generally quite porous (the porosity can be as high as $50 \mathrm{vol} \%$ ). This limitation can be overcome by combining the SHS reaction with a densification step. In the SHS/DC technique, hot, porous, ceramic bodies formed during the SHS reactions are consolidated to high density by the action of a pressure wave generated from the detonation of a high explosive and/or the impact of an explosively driven flyer plate. The SHS/DC technique has the merit of being less dependent on expensive facilities and higher in throughput than other techniques.

The SHS/DC technique has been studied by researchers at the US Army Ballistic Research Laboratory [22-25], and at New Mexico Tech. [26-28]. They demonstrated that, under appropriate conditions, near fully dense $\mathrm{TiB}_{2}, \mathrm{TiC}$ and $\mathrm{HfC}$ ceramics could be prepared using this technique. Valuable information regarding the effects of the powder characteristics, inert diluent, impurities, delay time and $C / M$ ratio (ratio of the explosive mass to the metal driving plate mass) on the synthesis and compaction was obtained. However, information about the mechanical properties of SHS/DC-prepared compacts is generally lacking. The objective of the research described in this paper was to evaluate the structural and mechanical 
properties of $\mathrm{TiB}_{2}$ and $\mathrm{TiC}$ compacts prepared by the SHS/DC technique, and to correlate the microstructural development and mechanical properties with the processing conditions.

\section{Experimental procedure}

2.1. SHS reaction and dynamic compaction

The starting materials were elemental powders of titanium, carbon and boron. The purity, particle size and supplier of the powders are summarized in Table I. Two different boron powders were used. The B-1 powder contained 1-5\% carbon, whereas the B-2 powder was $>99.5 \%$ pure. The particle sizes were selected as a compromise between the reduced reaction rate of larger particles, the inconvenience of handling smaller particles and the potential for surface contamination [23].

The B/Ti atomic ratio of $2: 1$ and $\mathrm{C} / \mathrm{Ti}$ atomic ratio of $0.95: 1$ were selected on the basis of the results of previous work. A stoichiometric $\mathrm{B} / \mathrm{Ti}$ ratio has been widely used, whereas a range of $\mathrm{C} / \mathrm{Ti}$ atomic ratios have been employed $(0.7$ to 1.19$)[9,22,23,28]$. Several researchers have suggested that the optimum $\mathrm{C} / \mathrm{Ti}$ atomic ratio for SHS/DC is $0.95[28,29]$. There are at least two reasons for the use of substoichiometric $\mathrm{C} / \mathrm{Ti}$ ratios [30]. First, the violent release of impurities can cause expulsion of titanium from the compact [31]. Secondly, at the elevated temperatures at which compaction occurs, non-stoichiometric TiC has a lower yield strength than stoichiometric $\mathrm{TiC}$ [32].

The $\mathrm{Ti}-\mathrm{B}$ and $\mathrm{Ti}-\mathrm{C}$ powders were dry mixed under an argon atmosphere for $12 \mathrm{~h}$ in a V-shaped, plastic, mechanical blender. Since no milling media was used, the possibility of contamination during mixing was minimal. The mixtures were uniaxially pressed into disc-shaped greenforms $(100 \mathrm{~mm}$ in diameter and $\sim 40 \mathrm{~mm}$ in thickness) under a pressure of greater than $20 \mathrm{MPa}$ using a hydraulic press. The relative densities of the resulting greenforms were $\approx 60 \%$ of the theoretical values. Subsequently, the greenforms were stored in a vacuum chamber to prevent oxidation.

The experimental set-up for the SHS/DC is shown in Fig. 1. This system was designed by Thadhani and co-workers [26-28] at New Mexico Tech. where the present shock-compaction experiments were performed. The system was made up of layers of gypsum wall-board which were centre-cored to a diameter slightly larger than that of the reactant greenforms. Two telescoping mild-steel rings of equal height were placed between the greenform and the gypsum to provide lateral containment during the reaction and

TABLE I Specifications of the starting materials

\begin{tabular}{lccl}
\hline Materiai & Purity & Particle size & Supplier \\
\hline Ti & $99.5 \%$ & -325 mesh & Micro Metals \\
B-1 & $>95 \%$ & -325 mesh & Aldrich \\
B-2 & $99.5 \%$ & -325 mesh & Atlantic \\
C (graphite) & $99.9 \%$ & $2 \mu \mathrm{m}$ & Consolid. Astron. \\
\hline
\end{tabular}

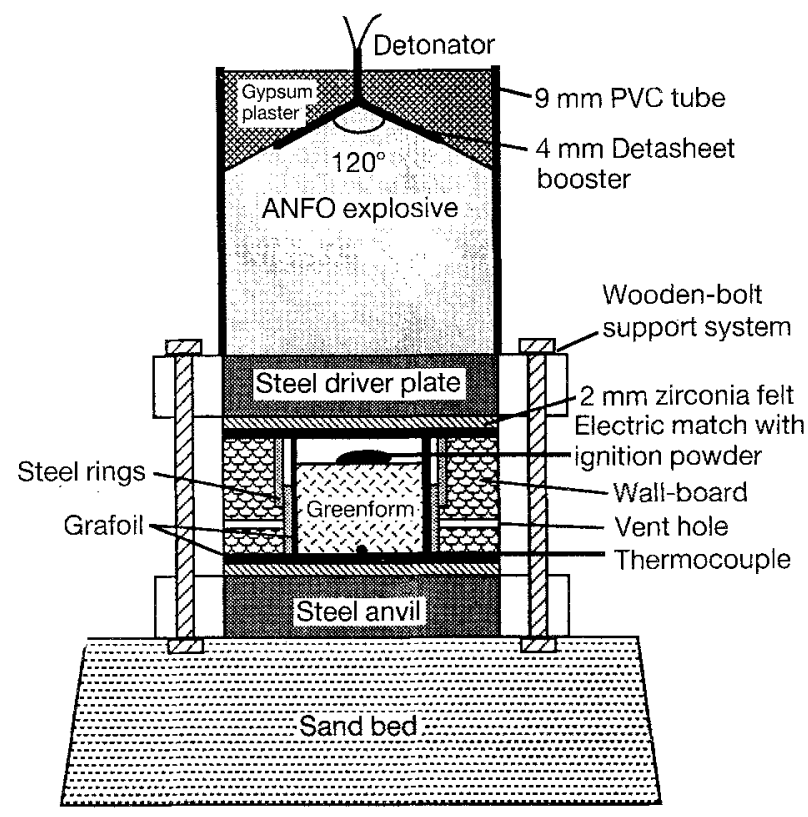

Figure 1 Experimental set-up for self-propagating high-temperature synthesis/dynamic compaction (SHS/DC).

subsequent compaction. The bottom ring and the gypsum block had four matching holes to vent gases released during the reaction. A Grafoil strip was placed between the steel ring and the greenform to provide thermal insulation and to prevent impurities from diffusing into the reacted compact. Circular driver plates and momentum traps made of highhardness steel (MIL SPEC 46100) were epoxied into wooden frames, and lined with zirconia felt and a Grafoil sheet.

The explosive loading assembly consisted of a PVC tube into which a $120^{\circ}$ gypsum cone was cast. The cone was lined with a Detasheet booster and filled with ANFO (ammonium nitrate mixed with $6 \mathrm{wt} \%$ fuel oil) explosive with a density of $900 \mathrm{~kg} \mathrm{~m}^{-3}$ and a detonation velocity of $3480 \mathrm{~m} \mathrm{~s}^{-1}$. Such a coneinitiated, explosive-charge assembly provided a much more uniform pressure loading than that generated using sweeping-wave initiation of the explosive charge $[26,28]$.

Loose powder of the same composition as that of the reactant mixture was placed on the top of the greenform. The powder was ignited by an electric match using a $115 \mathrm{~V}$ source. This in turn set off the reaction between titanium and boron or titanium and carbon in the greenform. The reaction wave travelled down toward the bottom surface of the greenform, and progress of the reaction was tracked using a chromel-alumel thermocouple attached to the surface of the momentum trap. The delay time (the time between reaction completion and explosive compaction) was varied in an attempt to enhance the densities of the compacts. The same experimental set-up was used for the synthesis of both $\mathrm{TiB}_{2}$ and $\mathrm{TiC}$.

The experimental conditions employed for the Ti-B and Ti-C systems are summarized in Table II. Flyer plates $200 \mathrm{~mm}$ in diameter were used for the $\mathrm{Ti}-\mathrm{B}$ system, whereas both 200 and $300 \mathrm{~mm}$ plates were used for the Ti-C system. The $C / M$ ratio reflects the pressure applied to the samples during the explosion. 
TABLE II Experimental Conditions for the SHS/DC of $\mathrm{TiB}_{2}$ and TiC

\begin{tabular}{|c|c|c|c|c|c|}
\hline Sample & Composition & $C / M$ ratio & $\begin{array}{l}\text { Time delay } \\
\text { (s) }\end{array}$ & $\begin{array}{l}\text { Fixture } \\
(\mathrm{mm})\end{array}$ & Precursor \\
\hline ТВ9224 & $\mathrm{B} / \mathrm{Ti}=2: 1$ & 0.2 & 10 & 200 & B-1 \\
\hline TB9225 & $\mathrm{B} / \mathrm{Ti}=2: 1$ & 0.2 & 5 & 200 & B-1 \\
\hline TB9244 & $\mathrm{B} / \mathrm{Ti}=2: 1$ & 0.2 & 10 & 200 & $\mathrm{~B}-2$ \\
\hline TB9245 & $\mathrm{B} / \mathrm{Ti}=2: 1$ & 0.2 & 15 & 200 & $\mathrm{~B}-2$ \\
\hline ТВ9246 & $\mathrm{B} / \mathrm{Ti}=2: 1$ & 0.2 & 20 & 200 & B-2 \\
\hline TC9223 & $\mathrm{C} / \mathrm{Ti}=0.95: 1$ & 0.6 & 5 & 200 & $\mathrm{C}$ \\
\hline ТС9241 & $\mathrm{C} / \mathrm{Ti}=0.95: 1$ & 0.4 & 5 & 200 & $\mathrm{C}$ \\
\hline TC9242 & $\mathrm{C} / \mathrm{Ti}=0.95: 1$ & 0.4 & 10 & 300 & $\mathrm{C}$ \\
\hline ТC9243 & $\mathrm{C} / \mathrm{Ti}=0.95: 1$ & 0.6 & 5 & 300 & $\mathrm{C}$ \\
\hline
\end{tabular}

While a low $C / M$ ratio might not generate a pressure sufficient to fully compact the sample, a high $C / M$ ratio could cause severe cracks and delamination in the sample due to the strong rarefaction forces and edge effects from the shock waves. In this research, a $C / M$ ratio of 0.2 was used for the Ti-B system, and $C / M$ ratios of 0.4 and 0.6 were used for the $\mathrm{Ti}-\mathrm{C}$ system. The delay time influences the temperature at which the sample is compacted. A longer delay time usually means a lower temperature. If the delay time is too long, compaction of the sample would be difficuit due to the lack of plasticity at low temperatures. If, however, the delay time is too short, delamination of the sample could occur due to the after-burn phenomenon, leading to a low density [26]. The optimum delay time depends on the system. Generally, the higher the reaction temperature, the longer the optimum delay time. The delay time was varied from $5-20 \mathrm{~s}$ in the experiments.

\subsection{Characterization}

Samples for analysis were cut using a diamond saw from four areas within the compacts. A schematic illustrating the locations of these four areas is given in Fig. 2. Three specimens were taken from the central region of the compact at varying distances from the impact surface (CT, CC, CB). Another specimen was taken from the area halfway between the centre of the compact and the edge (MC). Characterization of these specimens permitted an assessment of the axial and radial uniformity of the microstructural and mechanical properties.

Density. The densities were measured using the Archimedean water-displacement technique. The specimens were boiled in water for at least $2 \mathrm{~h}$ to ensure that all open pores were filled. The displacement of

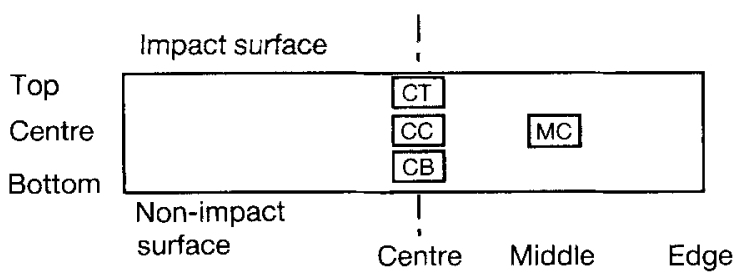

Figure 2 Cross-sectional view of compact. The four major areas from which samples were obtained to evaluate the uniformity in microstructural and mechanical properties: $\mathrm{C}$, centre; $\mathrm{T}$, top; $\mathrm{B}$, bottom; $\mathrm{M}$, middle. The first letter gives the radial position and the second the vertical position. water by each specimen was used to calculate the volume of the specimen. The density of stoichiometric $\mathrm{TiB}_{2}\left(4570 \mathrm{~kg} \mathrm{~m}^{-3}\right)$ and that of $\mathrm{TiC}_{0.9}\left(4880 \mathrm{~kg} \mathrm{~m}^{-3}\right)$ [30] were used to calculate the relative densities of the $\mathrm{TiB}_{2}$ and $\mathrm{TiC}$ samples, respectively.

Composition. The phase constituents in the SHS/DC compacts were determined by X-ray diffraction (XRD) using a Rigaku-Rotaflex diffractometer. An energy-dispersive spectrometer attached to a scanning electron microscope was used to qualitatively analyse the composition of each phase, especially that of any secondary phases or impurities. The compositions of selected phases were quantitatively analysed by electron microprobe analysis using a low- $z$ window detector capable of detecting boron and carbon. The titanium content in each phase was assayed against a pure titanium standard. The $\mathrm{B} / \mathrm{Ti}$ and $\mathrm{C} / \mathrm{Ti}$ atomic ratios were calculated by assuming that the only other element present was boron in the $\mathrm{TiB}_{2}$ grains, and carbon in the TiC grains.

Microstructure. The specimens were polished sequentially using diamond pastes with grit sizes of 45 , $30,15,6$ and $1 \mu \mathrm{m}$. The polished samples were etched prior to microstructural analysis using a solution of two parts $\mathrm{HNO}_{3}$, one part $\mathrm{CH}_{3} \mathrm{COOH}$ and one part $\mathrm{HF}$. The microstructure was examined by scanning electron microscopy (SEM) (Hitachi S-800). Grain sizes were determined from the SEM micrographs using the linear-intercept technique developed by Mendelson [33] according to the following equation

$$
D=\frac{1.57 C}{N M}
$$

where $D$ is the grain size, $C$ is the length of the test line, $M$ is the magnification of the micrograph, and $N$ is the number of grain-boundary intercepts. The proportionality constant relates the grain size to the intercept length of a random section though a space-filling array of grains. At least four micrographs were taken from each area in the compact. Ten lines were drawn randomly on each micrograph. The average grain size was obtained from over 40 line measurements which intercepted several hundred grains and therefore provided a statistically reliable value.

Microhardness. The microhardnesses were measured by the Knoop-indentation technique with a load of $0.1 \mathrm{~kg}$. The hardness tests were performed on the specimens from all four areas in the compact. Between 20 and 30 indentations were made in each area to 
obtain a statistically significant result. The effect of grain-boundary strength on the hardness was examined by increasing the load to 5 and $10 \mathrm{~kg}$.

Young's Modulus. The Young's moduli of selected materials were measured based on the velocity of sound through the specimens. The device used for the measurements consisted of a pulse circuit, a transducer and an oscilloscope. A trigger generator in the system activated an electric switch which produced large-amplitude pulses. These pulses were applied to a transducer which converted them into short ultrasonic pulses. The pulse wave bounced back and forth within the specimen. Each of the reflections was received by the transducer and a train of echoes could be observed on the oscilloscope. The velocity of sound in the specimen was obtained by dividing twice the thickness of the specimen by the time between two successive reflections. The Young's modulus, $E$, was calculated using the following equation [34]

$$
E=\rho v^{2}
$$

where $\rho$ is the density of the specimen, and $v$ is the sound velocity in the specimen.

Compressive Strength. The compressive strengths of selected samples were measured using an INSTRON system. The specimens, with dimensions of $3.6 \times 3.6$ $\times 7.2 \mathrm{~mm}^{3}$, were prepared using a surface grinder. The two ends of the specimens were carefully ground so that they were parallel to each other. Two larger blocks of the same material were used as spacers between the rams and the test bar. A spherical seat was used to ensure good alignment.

\section{Results and discussion}

\subsection{Physical appearance and density}

The SHS-reacted and explosively compressed compacts were usually recovered as single-piece plates $100 \mathrm{~mm}$ in diameter and $25 \mathrm{~mm}$ in thickness. The surfaces of the compacts were cleaned using an air jet. A photograph of the impact surface of TB9225 is shown in Fig. 3a. The surface was smooth with no major cracks, however, some edge delamination occurred. The steel ring maintained its shape with no signs of melting or failure. For some samples synthesized from the high-purity B-2 powder, the surfaces were much rougher, and the steel rings were distorted showing evidence of partial melting. Severe cracks were also observed in these samples.

The surfaces of the TiC samples were smooth, and the steel rings usually were not distorted (a photograph of the impact surface of TC9223 is shown in Fig. 3b). Two types of crack were observed for the TiC samples: large cracks often going through the samples, and smaller cracks with a much higher number density. These cracks resulted from residual strains which may have been caused by the temperature gradients within the compacts during cooling. It is expected that the outer surfaces of the compacts cooled at faster rates than did the cores. Should the residual thermal stresses not be released by plastic deformation, cracks could form as a result. The potential reasons for the $\mathrm{TiC}$ being more prone to cracking than $\mathrm{TiB}_{2}$ include
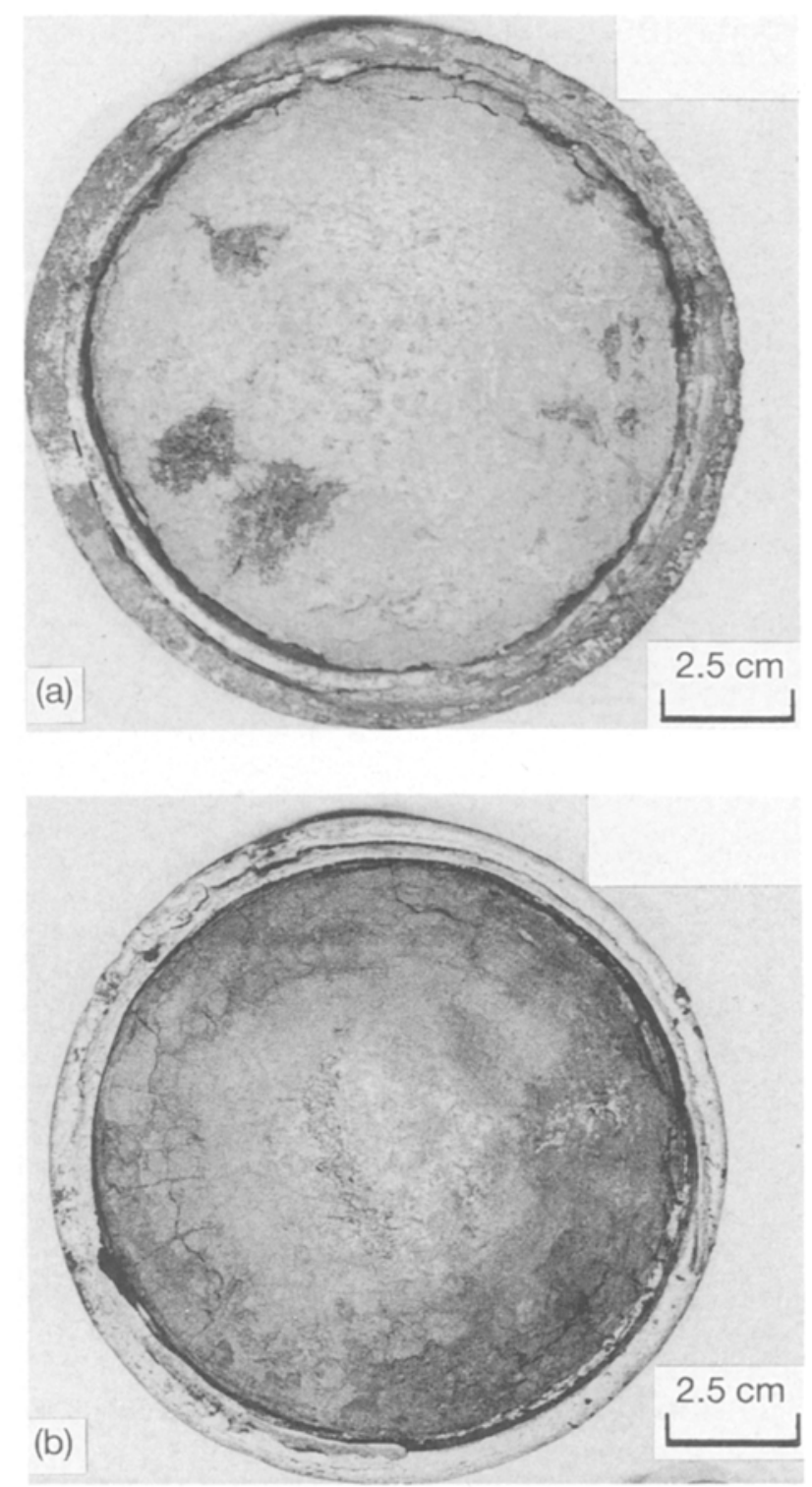

Figure 3 Photographs of $\mathrm{TiB}_{2}$ and $\mathrm{TiC}$ samples showing impact surfaces: (a) TB9225, and (b) TC9?23.

its lower heat of reaction and its higher coefficient of thermal expansion. A lower heat of reaction would result in a lower reaction temperature and less plasticity. A higher coefficient of thermal expansion would cause greater thermal stresses due to the different cooling rates across the compact.

The densities of the $\mathrm{TiB}_{2}$ and $\mathrm{TiC}$ compacts are presented in Table III. Near-theoretical densities were achieved under best-case conditions. Titanium carbide was more difficult to compact than $\mathrm{TiB}_{2}$. The relative density of TB 9225 was $99.3 \%$, whereas that of TC 9223 was $96.8 \%$. Since the high-temperature compressive yield strength of $\mathrm{TiB}_{2}$, at temperatures near those expected during SHS [35], is much greater than that of $\mathrm{TiC}$ [32], a mechanism other than plastic deformation was probably involved during dynamic compaction of $\mathrm{TiB}_{2}$. It has been proposed by Niiler et al. [23] that the melting point of $\mathrm{TiB}_{2}$ is exceeded during the SHS process whereas that of $\mathrm{TiC}$ is not. The presence of liquid would improve the compaction of $\mathrm{TiB}_{2}$ in comparison to that of $\mathrm{TiC}$.

The results revealed important relationships between the processing conditions and consolidation. 
TABLE III Structural and mechanical properties of $\mathrm{TiB}_{2}$ and $\mathrm{TiC}$ prepared using the SHS/DC technique

\begin{tabular}{|c|c|c|c|c|c|c|c|}
\hline \multirow{2}{*}{$\begin{array}{l}\text { Sample } \\
\text { TB9224 }\end{array}$} & \multirow{2}{*}{$\begin{array}{l}\text { Relative density } \\
(\%)\end{array}$} & \multicolumn{2}{|c|}{$\begin{array}{l}\text { Grain size } \\
(\mu \mathrm{m})\end{array}$} & \multicolumn{2}{|c|}{$\begin{array}{l}\text { Hardness }^{\mathrm{a}} \\
\left(\mathrm{kg} \mathrm{mm}^{-2}\right)\end{array}$} & \multirow[t]{2}{*}{$\begin{array}{l}\text { Young's modulus } \\
\left(\mathrm{kg} \mathrm{mm}^{-2}\right)\end{array}$} & \multirow[t]{2}{*}{$\begin{array}{l}\text { Comp. strength } \\
\left(\mathrm{kg} \mathrm{mm}^{-2}\right)\end{array}$} \\
\hline & & $\begin{array}{l}\text { CT: } \\
\text { CC: } \\
\text { CB: } \\
\text { MC: }\end{array}$ & $\begin{array}{l}20 \pm 4 \\
19 \pm 4 \\
16 \pm 3 \\
17 \pm 3\end{array}$ & $\begin{array}{l}\text { CT: } \\
\text { CC: } \\
\text { CB: } \\
\text { MC: }\end{array}$ & $\begin{array}{l}3351 \pm 443 \\
3291 \pm 310 \\
3309 \pm 274 \\
3193 \pm 375\end{array}$ & & \\
\hline TB9225 & 99.3 & $\begin{array}{l}\text { CT: } \\
\text { CC: } \\
\text { CB: } \\
\text { MC: }\end{array}$ & $\begin{array}{l}18 \pm 4 \\
18 \pm 3 \\
17 \pm 4 \\
17 \pm 4\end{array}$ & $\begin{array}{l}\text { CT: } \\
\text { CC: } \\
\text { CB: } \\
\text { MC: }\end{array}$ & $\begin{array}{l}3356 \pm 438 \\
3387 \pm 405 \\
3354 \pm 431 \\
3265 \pm 349\end{array}$ & $55900 \pm 1800$ & $188 \pm 50$ \\
\hline ТВ9244 & 93.0 & & & & & & \\
\hline TB9246 & 84.6 & $\begin{array}{l}\mathrm{CT}: \\
\mathrm{CC} \\
\mathrm{CB} \\
\mathrm{MC}\end{array}$ & $\begin{array}{l}23 \pm 4 \\
29 \pm 5 \\
29 \pm 7 \\
30 \pm 9\end{array}$ & $\begin{array}{l}\text { CT: } \\
\text { CC: } \\
\text { CB: } \\
\text { MC: }\end{array}$ & $\begin{array}{l}3273 \pm 610 \\
3277 \pm 393 \\
3297 \pm 385 \\
3213 \pm 474\end{array}$ & & \\
\hline ТС9223 & 96.8 & $\begin{array}{l}\text { CT: } \\
\text { CC: } \\
\text { CB: } \\
\text { MC: }\end{array}$ & $\begin{array}{l}43 \pm 16 \\
41 \pm 14 \\
36 \pm 10 \\
35 \pm 10\end{array}$ & $\begin{array}{l}\text { CT: } \\
\text { CC: } \\
\text { CB: } \\
\text { MC: }\end{array}$ & $\begin{array}{l}2999 \pm 202 \\
2992 \pm 356 \\
2925 \pm 256 \\
2985 \pm 289\end{array}$ & $46700 \pm 1400$ & $103 \pm 20$ \\
\hline ТC9241 & 93.9 & & & & & & \\
\hline ТС9242 & 93.7 & $\begin{array}{l}\text { CT: } \\
\text { CC: } \\
\text { CB: } \\
\text { MC: }\end{array}$ & $\begin{array}{l}36 \pm 13 \\
40 \pm 13 \\
29 \pm 11 \\
34 \pm 8\end{array}$ & $\begin{array}{l}\text { CT: } \\
\text { CC: } \\
\text { CB: } \\
\text { MC: }\end{array}$ & $\begin{array}{l}3012 \pm 437 \\
2834 \pm 303 \\
3068 \pm 185 \\
3005 \pm 202\end{array}$ & & \\
\hline ТC9243 & 94.3 & & & & & & \\
\hline
\end{tabular}

${ }^{a} \mathrm{CT}, \mathrm{CC}, \mathrm{CB}$ and $\mathrm{MC}$ refer to the positions illustrated in Fig. 2.

Comparison of TB9224 with TB9225 clearly demonstrated the effect of the delay time on the synthesis and compaction. The higher density of TB9225 relative to TB9224 was probably due to compaction of the former while the sample was at a higher temperature (a shorter delay time). A 5 s delay time seemed adequate for successful compaction of the samples when using the B-1 powder. For the samples prepared using the B2 powder, the delay time affected not only the density but also the cracking. Severe cracks occurred in both TB9244 and TB9246. The sample synthesized using a $15 \mathrm{~s}$ delay time (TB9245) showed the least cracking of the three samples.

The effect of the $C / M$ ratio on densification can be seen by comparing TC9223 and TC9241. Other processing conditions being the same, the higher $C / M$ ratio resulted in a higher density for TC9223 than in TC9241. The results also indicated the effect of the powder composition on the synthesis and consolidation of the samples. The TB9244 sample was synthesized using the same processing conditions as those used for TB9224 except that the former used the B-2 powder rather than the B-1 powder. The TB9244 sample showed severe cracks and was blown into pieces. This might be related to the different reactivities, and hence to the different temperatures generated using the two powders. Since the heat of reaction is lower for $\mathrm{TiC}$, carbon in the $\mathrm{B}-1$ powder may have acted as a diluent and reduced the violence of the SHS reaction.

\subsection{Composition}

X-ray diffraction (XRD) indicated that TB9225 consisted primarily of $\mathrm{TiB}_{2}$ with a small amount of $\mathrm{TiC}$
(Fig. 4a). There was no evidence of residual elemental titanium or boron, indicating that the synthesis reaction proceeded to completion. The $\mathrm{TiC}$ was the result of carbon impurities in the precursor boron powder (recall that B-1 contained $1-5 \% \mathrm{C}$ ). Electron microprobe analysis of the $\mathrm{TiB}_{2}$ grains showed that the $\mathrm{B} / \mathrm{Ti}$ atomic ratio was 1.75 . This corresponds to a boron atomic fraction of 0.64 , which is within experimental error of the lower limit of the stoichiometric range for $\mathrm{TiB}_{2}$ (boron atomic fraction $=0.65$ ) given in the $\mathrm{Ti}-\mathrm{B}$ phase diagram [36].

The XRD pattern of TB9246 is shown in Fig. $4 \mathrm{~b}$. Again, $\mathrm{TiB}_{2}$ was the major phase, with $\mathrm{TiC}$ being a minor constituent. The TiC content in TB9246 was much lower than that in the samples prepared using the B-1 powder. The carbon was probably from the precursor boron powder which contained $0.2 \%$ carbon according to the chemical analysis provided by the supplier. One of the peaks in the diffraction pattern has been attributed to TiCN. The formation of TiCN is possible because TiC and TiN can form an infinite solid solution. It is interesting to note that TB9225 did not show the presence of TiCN. The formation of TiCN in TB9246 might be related to the low density of the sample. Nitrogen in the pores might have dissolved into TiC grains to form TiCN.

The XRD pattern of TC9223 is shown in Fig. 5. The only phase present was $\mathrm{TiC}$. There was no evidence of residual elemental titanium or carbon. In addition, no secondary phases were observed; this is perhaps due to the use of high-purity starting materials. Electron probe microanalysis of the $\mathrm{TiC}$ grains showed that the $\mathrm{C} / \mathrm{Ti}$ atomic ratio was $0.85 \pm 0.04$. This corresponds to a carbon atomic fraction of 0.46 which is within the 


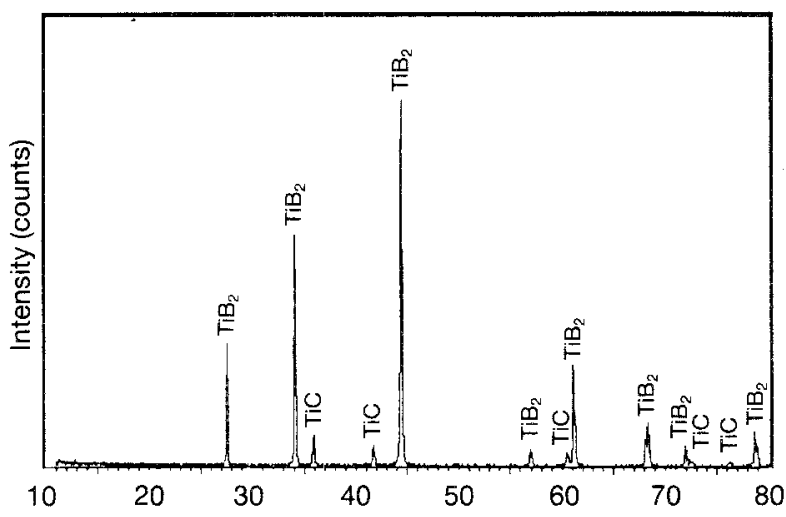

(a)

$2 \theta$ (degrees)

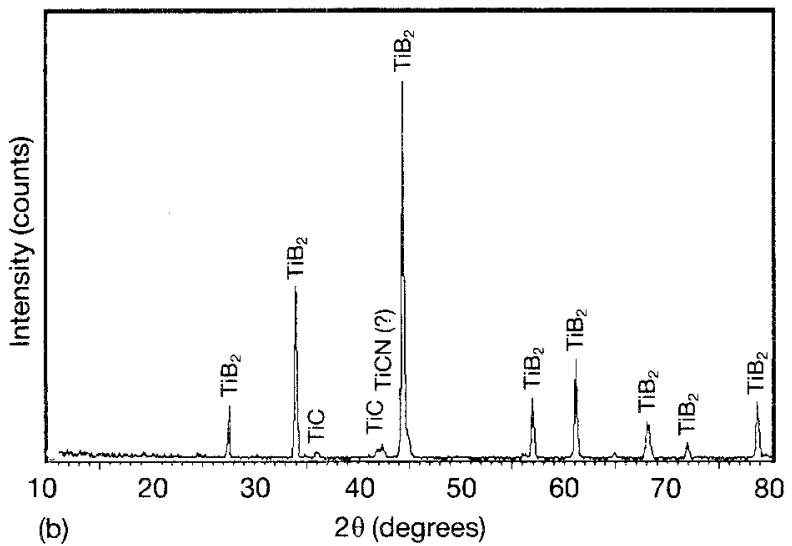

Figure 4 XRD patterns of: (a) TB9225, and (b) TB9246.

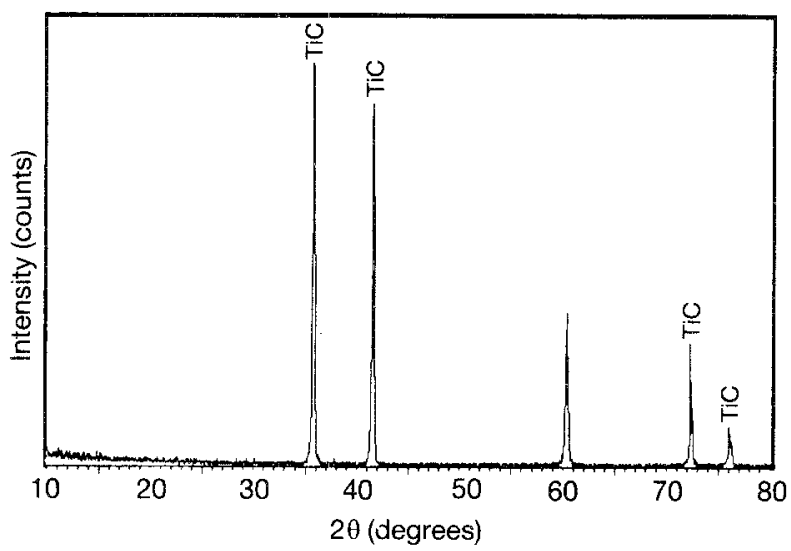

Figure 5 XRD pattern of TC9223.

stoichiometric range for $\mathrm{TiC}$ given in the $\mathrm{Ti}-\mathrm{C}$ phase diagram [36].

\subsection{Microstructure and grain size}

Fig. $6 \mathrm{a}$ and $\mathrm{b}$ show SEM micrographs of TB9225 (unetched) and TB9224 (etched), respectively. Both show a microstructure relatively free of porosity. The dark phase in the micrographs was due to $\mathrm{TiB}_{2}$ grains with shapes that were consistent with a section cut through randomly oriented, hexagonal, single crystals. This supported the postulate that the melting point of $\mathrm{TiB}_{2}$ was exceeded during the synthesis, since singlecrystal formation would only occur during cool down from a liquid phase [23].

The light-grey phase indicated by the letter $\mathrm{A}$ in Fig. 6a was identified as $\mathrm{TiC}$, with a $\mathrm{C} / \mathrm{Ti}$ atomic ratio of 0.80 determined by electron microprobe analysis. Some small but very bright white phases, indicated by the letter B, were also observed. These were found, by energy dispersive spectrum analysis, to be an alloy containing mainly $\mathrm{Ti}$ and $\mathrm{Fe}$ with small amounts of $\mathrm{Ni}, \mathrm{V}$ and $\mathrm{Cr}$. These metal impurities were probably present in the B-1 powder because such an alloy phase was not observed in either $\mathrm{TiC}$ or $\mathrm{TiB}_{2}$ prepared using the B-2 powder. Nevertheless, the amount of the alloy phase was much less than that of TiC. Both TiC and the metallic alloy were present primarily at the junctions of the $\mathrm{TiB}_{2}$ grains.

The $\mathrm{TiB}_{2}$ grains in samples prepared using the B-1 powder (TB9224 and TB9225) were relatively uniform in size with diameters between 15 and $20 \mu \mathrm{m}$ depending on their location in the compacts. It should be pointed out that almost every line drawn for grain-size analysis intercepted some secondary-phase particles. In order to avoid an inaccurate determination of the $\mathrm{TiB}_{2}$ grain size, the length intercepted by these secondary-phase particles was subtracted from the total length so that the presence of the secondary phase did not alter the $\mathrm{TiB}_{2}$-grain-size measurement.

For TB9246, which was prepared using the B-2 powder, no secondary phases were observed. The average grain size for TB9246 was greater than those for TB9225 and TB9224. This seemed reasonable, considering that the delay time for TB9246 was $20 \mathrm{~s}$ whereas those for TB9224 and TB9225 were 10 and $5 \mathrm{~s}$, respectively. Longer delay times would permit the growth of larger grains from the melt. Furthermore, the reaction temperature for TB9246 may also have been higher since the B-2 powder was purer than the B-1 powder. This was supported by our observation that the steel rings used to contain the samples prepared using the B-2 powder showed signs of melting. In contrast, the steel rings used for the samples prepared using the B-1 powder were not altered by the reaction.

Fig. 7 shows a SEM micrograph of TC9223 (etched). The TiC grains were more equiaxed than the $\mathrm{TiB}_{2}$ grains, however, the $\mathrm{TiC}$ grains were not of uniform size as was the case for the $\mathrm{TiB}_{2}$ samples. The TiC grains in some areas were coarse $(\approx 100 \mu \mathrm{m})$, whereas those in other areas were fine $(\approx 20 \mu \mathrm{m})$. The average was between 35 and $43 \mu \mathrm{m}$. The average grain size in the area close to the impact surface was slightly larger than that in the area close to the non-impact surface.

Some large pores (up to several micrometres in diameter) were present on the grain boundaries. They were most likely residual pores from the greenform. Small pores $(\ll 1 \mu \mathrm{m})$ were present predominantly within the TiC grains. They might have resulted from the formation of volatile products during the reaction.

\subsection{Hardness}

The Knoop microhardness measured for the three $\mathrm{TiB}_{2}$ samples was between 3200 and $3400 \mathrm{~kg} \mathrm{~mm}^{-2}$. The hardness values measured on samples from different areas were not significantly different. With such a low load $(0.1 \mathrm{~kg})$ and careful selection of locations, 

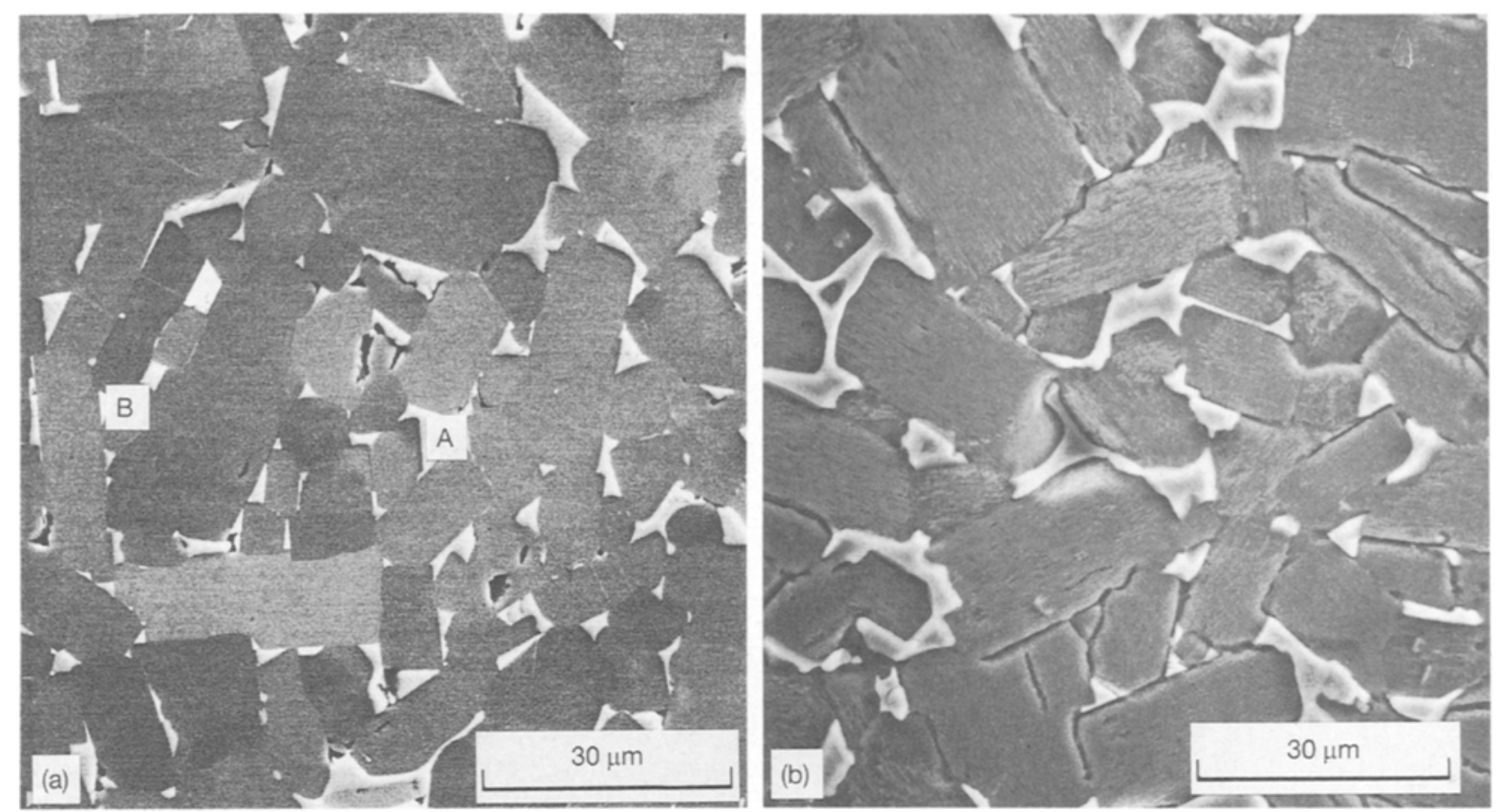

Figure 6 Scanning electron micrographs of $\mathrm{TiB}_{2}$ compacts: (a) TB9225 (unetched), and (b) TB9224 (etched).

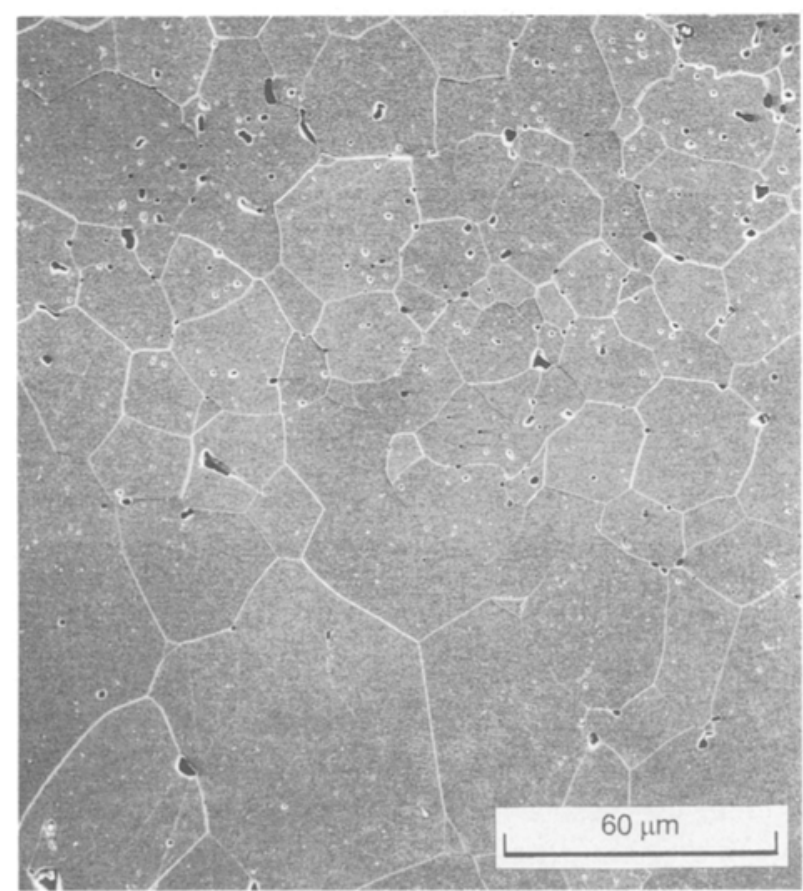

Figure 7 A scanning electron micrograph of TC9223 (etched).

indentations were made within $\mathrm{TiB}_{2}$ grains so that the effect of the grain boundaries on the hardness was greatly reduced. The reported hardness for $\mathrm{TiB}_{2}$ ranges from 2710 to $3900 \mathrm{~kg} \mathrm{~mm}^{-2}$ depending on the synthesis method employed, the microstructure of the specimen and the test conditions [37]. The hardness measured by Riley and Niiler [22] under the same load $(0.1 \mathrm{~kg})$ was between 1800 and $2600 \mathrm{~kg} \mathrm{~mm}^{-2}$ for SHS/DC TiB ${ }_{2}$, and between 2500 and $3500 \mathrm{~kg} \mathrm{~mm}^{-2}$ for hot-pressed $\mathrm{TiB}_{2}$. The hardness of $\mathrm{TiB}_{2}$ measured by Honak [38] under a load of $0.1 \mathrm{~kg}$ was $3400 \mathrm{~kg} \mathrm{~mm}^{-2}$.
The Knoop microhardness values for TC9223 and TC9242 were approximately $3000 \mathrm{~kg} \mathrm{~mm}^{-2}$. The hardness values measured for samples from different areas were similar. The reported hardness for $\mathrm{TiC}$ ranges from 1500 to $3200 \mathrm{~kg} \mathrm{~mm}^{-2}$. The hardness reported by Keiffer and Kölbl [39] for the same load used in this research $(0.1 \mathrm{~kg})$ was $3200 \mathrm{~kg} \mathrm{~mm}^{-2}$. Riley and Niiler [22] reported values between 1500 and $2700 \mathrm{~kg} \mathrm{~mm}^{-2}$ for SHS/DC TiC, and between 2400 and $3100 \mathrm{~kg} \mathrm{~mm}^{-2}$ for hot-pressed TiC. The discrepancy between the reported values has been attributed to differences in the microstructures of the specimens and/or the test conditions [5].

For the SHS/DC-prepared $\mathrm{TiB}_{2}$ and $\mathrm{TiC}$ compacts, hardness measurements were usually made using a load less than $0.3 \mathrm{~kg}[23,28]$. This microhardness did not, however, reflect the hardness of the compacts as bulk materials. It was therefore important to examine the effect of test load on the hardness. Knoop hardnesses were measured under loads of 5 and $10 \mathrm{~kg}$.for selected samples. The results are shown in Fig. 8a and b. When the test load was increased from 0.1 to $5 \mathrm{~kg}$, the measured hardness of TB9225 decreased from $\approx 3400$ to $1200 \mathrm{~kg} \mathrm{~mm}^{-2}$, whereas that of TC9223 decreased from 3000 to $1500 \mathrm{~kg} \mathrm{~mm}^{-2}$. Further increases in the load did not result in significant further reductions in the hardness. Under the larger loads, the indentation covered more than one grain. The collapse of the grain boundaries resulted in the low value of the measured hardness. This suggested weak grainboundary bonding, which might be inherent for materials prepared using the SHS/DC technique. The SHS/DC process is very rapid; consequently, there may not have been sufficient time for the atoms to rearrange to produce atomic-level bonding between the grains. In addition, the more rapid cooling of the outer surfaces compared to the cores could have 


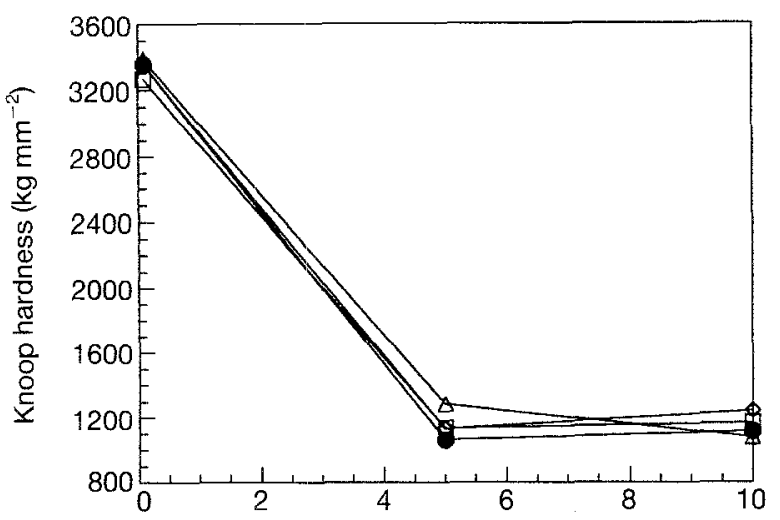

(a)

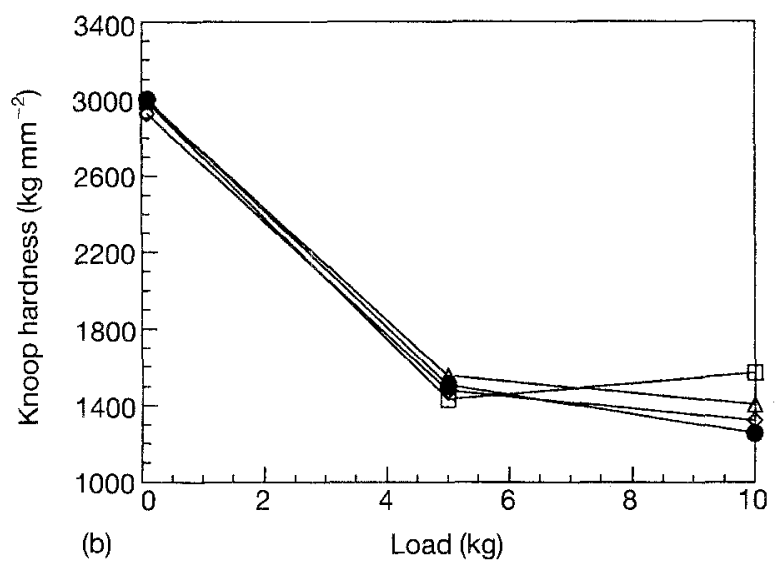

Figure 8 Effect of a test load on the measured hardness of (a) TB9225, and (b) TC9223: $(\triangle) \mathrm{CC},(\bullet) \mathrm{CT},(\diamond) \mathrm{CB}$, and $(\square) \mathrm{MC}$.

caused extensive stresses or microcracks along the grain boundaries. Microcracks were often observed in the high-magnification micrographs. A microgap is clearly evident along the two neighboring $\mathrm{TiB}_{2}$ grains in Fig. 9.

The decrease in hardness with test load was less dramatic for $\mathrm{TiC}$ than for $\mathrm{TiB}_{2}$. In going from a test

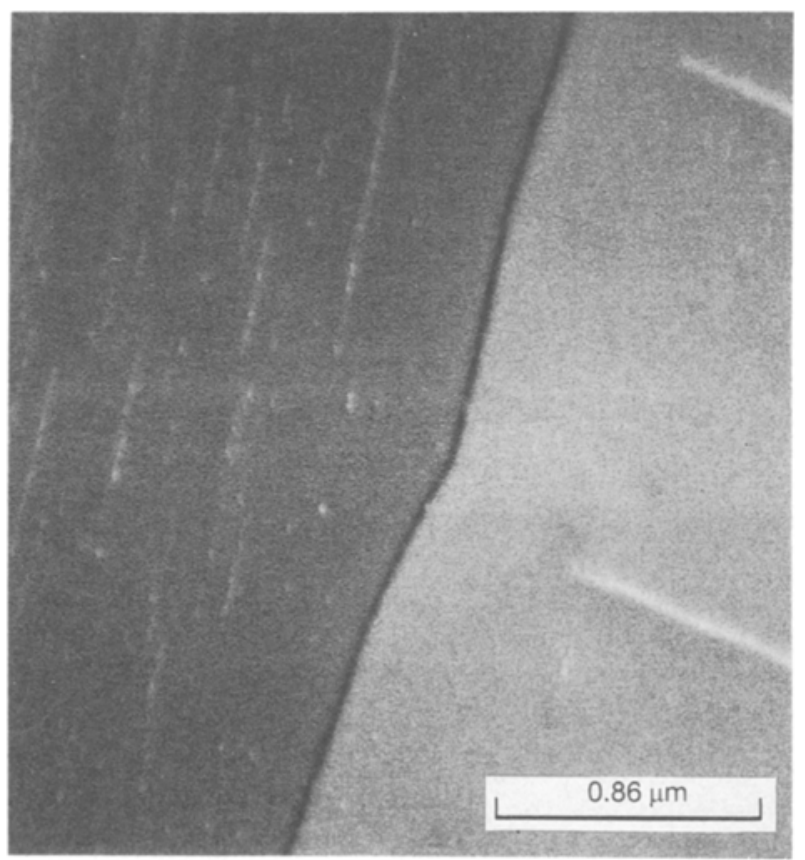

Figure 9 A scanning electron micrograph illustrating a microcrack along a boundary between two $\mathrm{TiB}_{2}$ grains. load of 0.1 to $5.0 \mathrm{~kg}$, the hardness of TiC decreased by $50 \%$ whereas that of $\mathrm{TiB}_{2}$ decreased by $65 \%$. This result could be due to the larger grain size and hence to a lower amount of grain boundaries in TiC. It also suggests that the grain-boundary strength in $\mathrm{TiC}$ was greater than in $\mathrm{TiB}_{2}$.

In order to examine the effect of grain-boundary bonding on the hardness, TB9225 and TC9223 were annealed for $7.5 \mathrm{~h}$ at 1500 or $2000^{\circ} \mathrm{C}$ in argon. A boron-nitride crucible was used for $\mathrm{TiB}_{2}$, and a graphite crucible for $\mathrm{TiC}$. The effects of annealing on the hardness are shown in Fig. 10a and b. Annealing TB9225 at $1500^{\circ} \mathrm{C}$ increased the hardness from about 1100 to over $1300 \mathrm{~kg} \mathrm{~mm}^{-2}$, and annealing at $2000^{\circ} \mathrm{C}$ further improved the hardness to $1550 \mathrm{~kg} \mathrm{~mm}^{-2}$ when measured under a load of $5 \mathrm{~kg}$. The improvement in hardness could be related to either an increased grain size, an increased grain-boundary strength, or both. However, the fact that the hardness values increased under a load of $5 \mathrm{~kg}$ but not under a load of $10 \mathrm{~kg}$ suggested that the grain-boundary strength, and not the grain size, was the key factor. Otherwise, the hardness should also increase under a load of $10 \mathrm{~kg}$. While the grain-boundary bonding was improved by annealing, the improvement was not enough for the grain boundaries to withstand loads $\geq 10 \mathrm{~kg}$. It should be pointed out that annealing may not be desirable because it will reduce the cost effectiveness of the SHS/DC process. The intention here was to demonstrate the concept of improving grain-boundary strength to produce engineering materials with high bulk hardnesses.
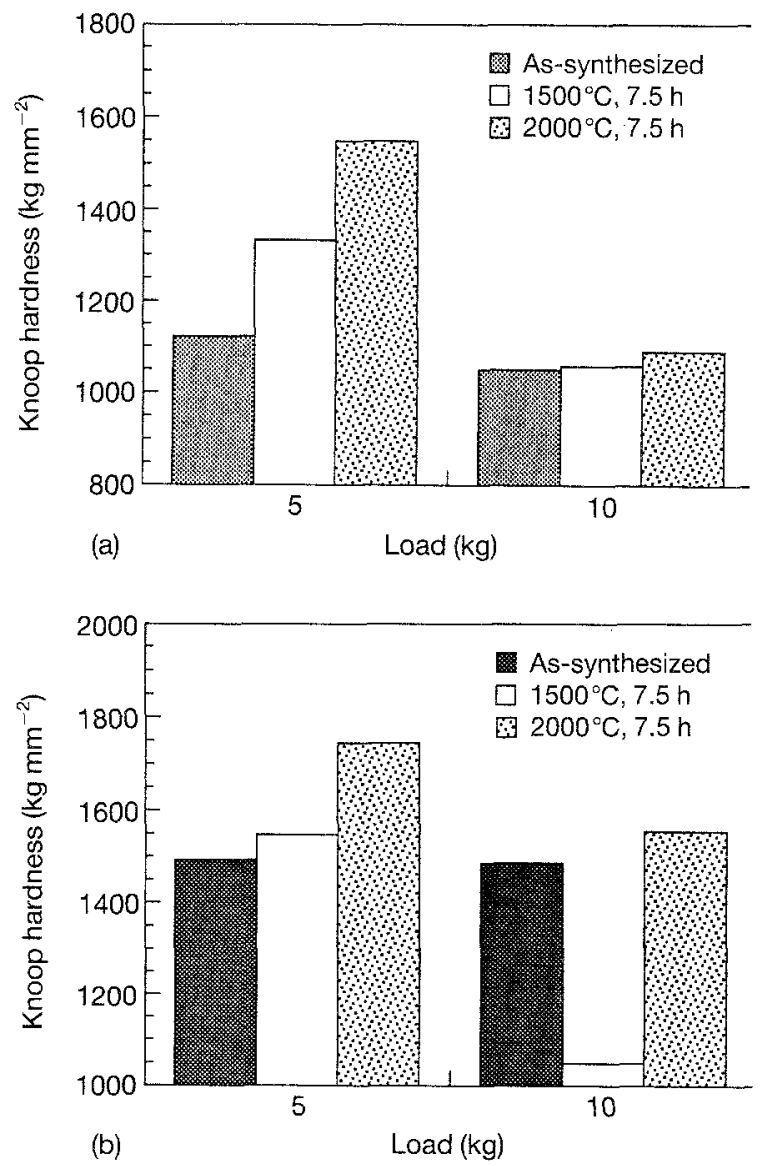

Figure 10 The effect of annealing temperature on hardness measured under different loads for (a) TB9225, and (b) TC9223. 
For TC9223, annealing at $1500^{\circ} \mathrm{C}$ did not increase the hardness (the exceptional data point under a test load of $10 \mathrm{~kg}$ was probably due to the non-uniformity of the $\mathrm{TiC}$ microstructure). Annealing at $2000^{\circ} \mathrm{C}$ for $7.5 \mathrm{~h}$ significantly increased the hardness measured under a test load of $5 \mathrm{~kg}$, but it did not significantly increase the hardness measured under a test load of $10 \mathrm{~kg}$. The less dramatic effect of annealing on the hardness of $\mathrm{TiC}$, compared to $\mathrm{TiB}_{2}$, might be due to the stronger initial grain-boundary bonding or the higher melting point for $\mathrm{TiC}$.

\subsection{Young's modulus and compressive strength}

The Young's modulus of TB9225 was 55900 $\pm 1800 \mathrm{~kg} \mathrm{~mm}^{-2}$, and that of TC9223 was 46700 $\pm 1400 \mathrm{~kg} \mathrm{~mm}^{-2}$ (for averages of nine and seven measurements, respectively). The modulus reported by Kotelnikov et al. [40] and Samsonov [41] for hotpressed $\mathrm{TiB}_{2}$ was $54000 \mathrm{~kg} \mathrm{~mm}^{-2}$. The Young's modulus of $\mathrm{TiC}$ reported in the literature varies widely (31 600 [42], 46000 [43] and $54200 \mathrm{~kg} \mathrm{~mm}^{-2}$ [44]). The present result was in good agreement with the value reported by Samsonov [43].

The average compressive strength of TB9225 was $188 \pm 50 \mathrm{~kg} \mathrm{~mm}^{-2}$, which was in excess of that reported in the literature for hot-pressed $\mathrm{TiB}_{2}$. The compressive strength of hot-pressed $\mathrm{TiB}_{2}$ measured by Kotelnikov et al. [40] was $165 \mathrm{~kg} \mathrm{~mm}^{-2}$, whereas that reported by Samsonov [41] was $135 \mathrm{~kg} \mathrm{~mm}^{-2}$. It should be pointed out that we expected the compressive strength to vary because of the difficulty in carrying out the compression test. The test required near-perfect alignment of the test system. Any point contacts between the specimen and spacers, or between the spacers and rams could cause a local failure of the specimen or spacers, resulting in a false measurement. Furthermore, internal defects in the specimens such as cracks could also affect the test results. For the specimen which had the highest compressive strength, failure was accompanied by a loud explosion-like sound; this was much louder than for the other samples.

Fig. 11 shows a cleavage surface for TB9225 after the compression test. It shows both intergranular and transgranular fracture. Note that during the hardness test, the fracture mode was observed to be predominantly intergranular. The existence of the transgranular fracture in the compression-ruptured samples might be related to the sudden release of energy stored in the sample during the test. This, along with the fact that the compressive strength of the SHS/DC-prepared $\mathrm{TiB}_{2}$ was comparable to that of the hot-pressed $\mathrm{TiB}_{2}$, indicated that the relatively weak grain boundaries did not result in a reduction in the compressive strength.

The compressive strength of TC9223 was 103 $\pm 20 \mathrm{~kg} \mathrm{~mm}^{-2}$; this was lower than the value reported by Samsonov $\left(138 \mathrm{~kg} \mathrm{~mm}^{-2}\right)$ [43]. Extensive cracks present in the TiC sample may have caused local failures in the sample.

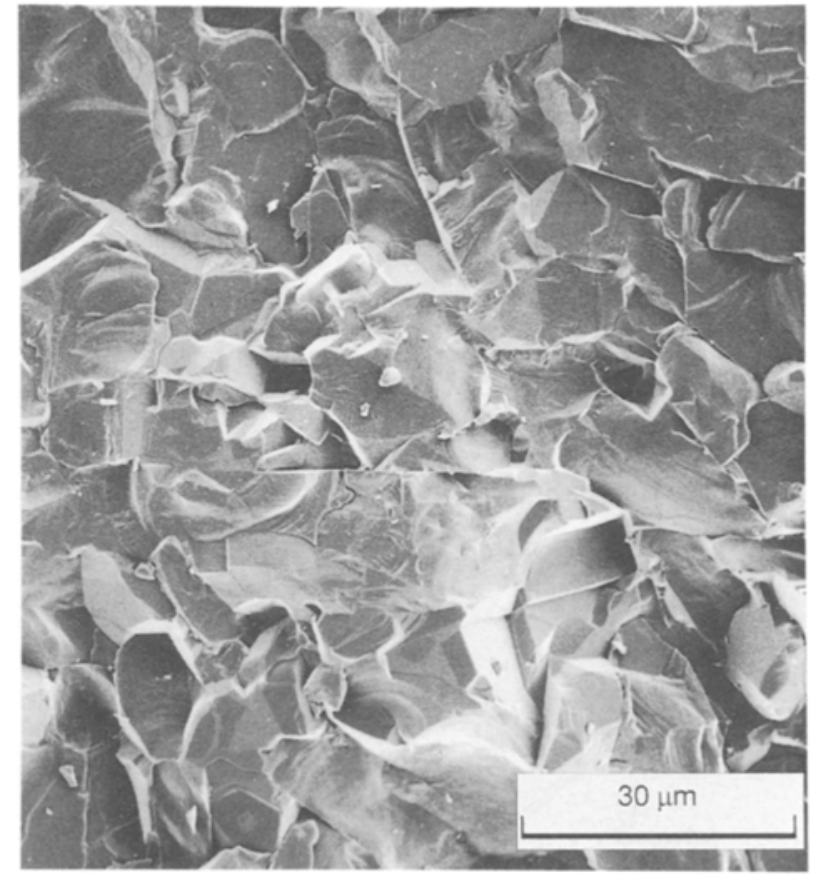

Figure 11 A cleavage surface for TB9225 after the compression test, illustrating both intergranular and transgranular fracture.

\section{Conclusion}

Titanium-diboride and titanium-carbide compacts were successfully fabricated by the SHS/DC technique. The compacts were $100 \mathrm{~mm}$ in diameter and $25 \mathrm{~mm}$ thick. Densities higher than $99 \%$, and $96.8 \%$ of the theoretical densities were achieved for $\mathrm{TiB}_{2}$ and $\mathrm{TiC}$, respectively. The microhardness, elastic modulus, and compressive strength of the $\mathrm{TiB}_{2}$ were $\sim 3300$, 55900 and $188 \mathrm{~kg} \mathrm{~mm}^{-2}$, respectively. These values are comparable to those reported for hot-pressed $\mathrm{TiB}_{2}$. While the microhardness and elastic modulus of the TiC compacts ( $\sim 3000$ and $46700 \mathrm{~kg} \mathrm{~mm}^{-2}$, respectively) were comparable to those for hot-pressed $\mathrm{TiC}$, the compressive strength $\left(103 \mathrm{~kg} \mathrm{~mm}^{-2}\right)$ was lower because of extensive cracks in the TiC compacts.

An important finding in this work was that compacts prepared using the boron powder which contained $1-5 \%$ carbon had higher densities and less cracking than those prepared using either the purer boron powder $(0.2 \%$ carbon) or pure carbon. This suggests that less-pure boron powders can be employed in the production of dense, $\mathrm{TiB}_{2}$ ceramics via SHS/DC. Finally, we concluded that the grain-boundary strength of the $\mathrm{TiB}_{2}$ and $\mathrm{TiC}$ prepared by the SHS/DC process was relatively weak, this is, perhaps, due to the rapid heating, compression and cooling involved in the process.

\section{Acknowledgements}

The authors acknowledge financial support for this research from the US Army Ballistic Research Laboratory (Contract No. DAAA15-91-C-0088). LTT acknowledges additional support from the National Science Foundation Presidential Young Investigator Program (Grant No. CTS-9158527). We thank Dr Naresh Thadhani and Andrew Grebe of the Center for 
Explosive Technologies Research at New Mexico Tech. for preparation of the compacts, and Dr Andrus Niiler of the Ballistic Research Laboratory for valuable discussions.

\section{Rèferences}

1. M. L. WILKINS, C. F. Cline and C. A. HONODEL, Fourth Progress Report of the Light Armor Program, UCRL50694, Lawrence Radiation Laboratory, University of California, Livermore (1969).

2. M. L. WILKINS, R. L. LANDINGHAM, C. A. HONODEL, Fifth Progress Report of the Light Armor Program, UCRL50980, Lawrence Radiation Laboratory, University of California, Livermore (1971).

3. G. V. SAMSONOV and B. A. KOVENSKAYA, in "Boron and refractory borides", edited by V. I. Matkovich (SpringerVerlag, Berlin, 1977) p. 5.

4. L. E. TOTH, "Transition metal carbides and nitrides" (Academic Press, New York, 1971).

5. E. K. STORMS, "The refractory carbides" (Academic Press, New York, 1967).

6. O. Yamada, Y. MiYamoto and M. Koizumi, Amer. Ceram. Bull. 64 (1985) 319.

7. J. B. HOLT, D. D. KINGMAN and G. M. BIANCHINI, Mater. Sci. Engng. 71 (1985) 321.

8. R. W. RICE and W. J. McDONOUGH, J. Amer. Ceram. Soc. 68 (1985) C-122.

9. J. B. HOLT and Z. A. MUNIR, J. Mater. Sci. 21 (1986) 251.

10. K. HIRAO, Y. MIYAMOTO and M. KOIZUMI, YogyoKyokai-Shi 95 (1987) 23.

11. Z. A. MUNIR, Amer. Ceram. Bull. 67 (1988) 342.

12. S. D. DUNMEAD, D. W. READY and C. E. SEMLER, $J$. Amer. Ceram. Soc. 72 (1989) 2318.

13. Z. A. MUNIR and U. ANSELMI-TAMBURINI, Mater. Sci. Reports 3 (1989) 277.

14. Y. CHOI, M. E. MULLINS, K. WIJAYATILLEKE and J. K. LEE, High Temp. Tech. 8 (1990) 227.

15. J. TRAMBUKIS and Z. A. MUNIR, J. Amer. Ceram. Soc. 73 (1990) 1240.

16. M. ESLAMLOO-GRAMI and Z. A. MUNIR, ibid. 73 (1990) 1235.

17. C. C. AGRAFIOTIS, J. LIS, J. A. PUSZYNSKI and V. HLAVACEK, ibid. 73 (1990) 3514.

18. H. C. YI and J. J. MOORE, J. Mater. Sci. 25 (1990) 1159

19. S. C. DEEVI, ibid. 26 (1991) 2662.

20. R. W. RICE, ibid. 26 (1991) 6533.

21. J. ZENG and Y. MIYAMOTO, J. Amer. Ceram. Soc. 74 (1991) 2197.

22. M. A. RILEY and A. NIILER, Memorandum Report BRLMR-3574, US Army Ballistic Research Laboratory, Aberdeen Proving Ground, MD (1987).
23. A. NIILER, L. J. KECSKES, T. KOTTKE, P. H. NETHERWOOD jr. and R. F. BENCK, Technical Report BRL-TR2951, US Army Ballistic Research Laboratory, Aberdeen Proving Ground, MD (1988).

24. A. NIILER, L. J. KECSKES and T. KOTTKE, in "Combustion and plasma synthesis of high temperature materials", edited by Z. A. Munir and J. B. Birch (VCH, New York, 1990) p. 309 .

25. L. J. KECSKES, R. F. BENCK and P. H. NETHERWOOD, J. Amer. Ceram. Soc. 73 (1990) p. 383.

26. H. A. GREBE, A. ADVANI, N. N. THADHANI and T KOTTKE, private communication.

27. A. H. ADVANI, N. N. THADHANI, H. A. GREBE, R. HEAPS, C. COFFIN and T. KOTTKE, J. Mater. Sci. 27 (1992) 3309

28. H. A. GREBE, PhD thesis, New Mexico Tech, Socorro, New Mexico (1993)

29. O. YAMADA, Y. MiYA Moto and M. KoIZUMi, $J$. Amer. Ceram. Soc. 70 (1987) C-206.

30. J. C. LaSALVIA, L. W. MEYER and M. A. MEYERS, ibid 75 (1992) 592

31. L. J. KECSKES and A. NIILER, ibid. 72 (1989) 655.

32. D. B. MIRACLE and H. A. LIPSITT, ibid. 66 (1983) 592.

33. M. I. MENDELSON, ibid. 52 (1969) 443.

34. C. KITTEL, "Introduction to solid state physics" (John Wiley, New York, 1953)

35. J. R. RAMBERG and W. S. WILliAMS, J. Mater. Sci. 22 (1987) 1815

36. T. B. MASSALAKI (editor-in chief) "Binary alloy phase diagrams", Vol. 1 (American Society for Metals, Metals Park, Ohio, 1986).

37. I. J. McCOLM, "Ceramic hardness" (Plenum Press, New York, 1990).

38. E. R. HONAK, Thesis, Tech. Hochsch. Graz (1951).

39. R. KIEFFER and F, KÖLBL, Powder Metall. Bull. 4 (1949) 4

40. R. B. KOTELNIKOV, S. N. BASHLYKOV, Z. G. GALIACBAROV and A. J. KASHTANOV, "Especially high melting elements and compounds" (Isdatel'stvo Metallurgija, Moscow, 1969).

41. G. V. SAMSONOV, "Refractory compounds" (Moscow, Metallurgizdat, 1963).

42. W. D. KINGERY, H. K. BOWEN and D. R. UHLMANN, "Introduction to ceramics" (John Wiley, New York, 1976).

43. G. V. SAMSONOV, "Plenum press handbook of hightemperature materials", No.2, Properties Index (Plenum Press, New York, 1962)

44. C. H. McMURTRY, W. D. G. BOECKER, S. G SESHADRI, J. S. ZANGHI and J. E. GARNIER, Amer. Ceram. Bull. 66 (1987) 325.

Received 24 April

and accepted 9 July 1993. 